\title{
Modeling the Effect of Hydration on the Electronic and Vibrational Properties of AZT
}

\author{
Mohamed A. M. El-Mansy 1,2 (D), Ahmed M. Bayoumy ${ }^{3}$, Hend Ezzat ${ }^{4}$ (D), Nayera El-Sayed ${ }^{5}$, \\ Hanan Elhaes 6 ${ }^{(1)}$, Osama Osman ${ }^{7}$ (D), Abdel Aziz Mahmoud ${ }^{7}$ (D), Asmaa Ibrahim ${ }^{7}$ (D), \\ Medhat Ibrahim $7, *$ (D)
}

1 Molecular Modeling Simulation Lab., Department of Physics, Faculty of Education, Ain Shams University, Roxy, Cairo, Egypt; mohamed_mansy878@yahoo.com (M.E.M.);

2 Condensed Matter Theory Group, Department of Physics, College of Science and Arts, Qassim University, ArRass, 51921, Saudi Arabia

3 Biophysics Branch, Physics Department, Faculty of Science, Ain Shams University, Cairo, Egypt; bmahmed100@yahoo.com (A.B.);

4 Nano Technology Unit, Space lab, Solar and Space Research Department, National Research Institute of Astronomy and Geophysics (Nano NRIAG), 11421 Helwan, Cairo, Egypt; hend_ahmed16@yahoo.com (H.E.);

5 Department of Physics, Faculty of Science, Mansoura University, Mansoura 35516, Egypt; nayeramohammed13@gmail.com (N.E.S.);

6 Physics Department, Faculty of Women for Arts, Science and Education, Ain Shams University, 11757 Cairo, Egypt; medahmed@yahoo.com (H.E.);

7 Molecular Spectroscopy and Modeling Unit, Spectroscopy Department, National Research Centre, 33 El-Bohouth St., 12622 Dokki, Giza, Egypt; medahmed6@yahoo.com (M.I.);

* Correspondence: medahmed6@yahoo.com;

Scopus Author ID 8641587100

Received: 6.08.2020; Revised: 6.09.2020; Accepted: 8.09.2020; Published: 10.09.2020

\begin{abstract}
The 3'-azido-3'-deoxythymidine, which is termed AZT, was introduced as anti-human immunodeficiency virus HIV. AZT is supposed to interact with water molecules forming two hydration shells. In the first shell, five water molecules were surrounding five active sites. Each water molecule then further interacted with two water molecules forming the second hydration shell. The computational note is dedicated on the basis of density functional theory (DFT). So that, DFT:B3LYP/6-31G(d,p) was used to follow up on the changes in AZT as a result of hydration. The DFT was used to calculate total dipole moment (TDM), HOMO/LUMO bandgap energies, molecular electrostatic potential (MESP), and IR frequencies.
\end{abstract}

Keywords: AZT; Hydration; DFT; TDM; MESP; IR.

(C) 2020 by the authors. This article is an open-access article distributed under the terms and conditions of the Creative Commons Attribution (CC BY) license (https://creativecommons.org/licenses/by/4.0/).

\section{Introduction}

The human immunodeficiency virus (HIV) is a lentivirus, one of the retrovirus subgroups, which causes viral infection (HIV) and syndrome, namely acquired immunodeficiency syndrome (AIDS). In a progressive manner, the failure of the immune system takes place in the condition of AIDS and allows all types of life-threatening infections to thrive [1]. HIV infection causes severe depletion of CD4 expressing cells, which include T lymphocytes, monocytes, and macrophages, leading to profound immunosuppression [2]. Antiviral drug azidothymidine 63, also known as AZT and zidovudine, is useful in the treatment of AIDS as an agent impeding the human immunodeficiency virus replication process [3]. AZT, the first compound that has been approved by the Food and Drug 
Administration (FDA-USA), was long used as a monotherapy for HIV infection. Zidovudine is $3^{\prime}$-azido-3'-deoxytimidine (36.1.26), is synthesized from $1-\left(2^{\prime}\right.$-deoxy-5'-O-trityl- $\beta$-dlyxosyl)thymine, which is treated with methansulfonyl chloride in pyridine to make the corresponding mesylate 36.1.24. Replacing the methyl group with an azide group using lithium azide in dimethylformamide makes the product 36.1 .25 with an inverted configuration at C3 of the furanosyl ring. Heating this in $80 \%$ acetic acid removes the trityl protection, giving zidovudine [4]. Zidovudine is an analog of thymidine that inhibits the replication of the AIDS virus. It also turned into mono-, di-, and triphosphates by the same cellular enzymes that catalyze the phosphorylation of thymidine and thymidine nucleosides.

Zidovudine-triphosphate is then included in the terminal fragment of the growing chain of viral DNA by viral reverse transcriptase, thus causing the viral DNA chain to break apart in cells infected with the virus [4]. This drug belongs to the class of nucleoside reverse transcriptase (RT) inhibitors. During the clinical studies utilizing zidovudine as monotherapy, it was apparent that the antiviral effect diminished over time for many patients, and the loss in activity was ascribed to the acquisition of mutations within the RT sequence. The magnitude of activity loss generally corresponded to the number of acquired mutations. The RT that has been sequenced from patients whose virus has become highly resistant to zidovudine contains four or more mutations at M41L, D67N, K70R, L210W, T215, and K219Q [5]. DSC curve of AZT shows a sharp endothermic peak that corresponds to melting in the range of $120-124^{\circ} \mathrm{C}$. The IR spectrum of AZT shows the stretching bands in the $3500-3200 \mathrm{~cm}^{-1}$ wavenumber region assigned to $v_{\mathrm{s}}$ and $v_{\mathrm{as}} \mathrm{OH}$ stretching, $\mathrm{OH}$-bending mode at $1630-1600 \mathrm{~cm}^{-1}$, a band at $2102 \mathrm{~cm}^{-1}$ assigned to $v$ of $\mathrm{C}=\mathrm{N}=\mathrm{N}=\mathrm{N}$ (azide group), a band at $1694 \mathrm{~cm}^{-1}$ assigned to $\mathrm{C}=\mathrm{O}$, a band at $1385 \mathrm{~cm}^{-1}$ assigned to $\mathrm{CH}_{2}$, and $1281 \mathrm{~cm}^{-1}$ assigned to $\mathrm{C}-\mathrm{O}-\mathrm{C}$ and $\mathrm{C}-\mathrm{OH}$. DSC curves show an endothermic event at $309^{\circ} \mathrm{C}[6]$.

Over the past years, the attention of many researchers were paid to AZT-based therapeutics according to its medicinal properties. AZT properties show wide applications, including not only an antiviral drug in HIV treatment but also antitumor agents [7], antioxidants [8], antimalarial agents [9], and AZT prodrugs for anticancer and antiviral effects [10]. Recently, a series of AZT was synthesized then screened them against Gram-negative as well as Gram-positive strains to act as antibacterial regulating metastasis of breast cancer cells [11].

Molecular modeling is a class of computational work widely used for elucidating the physical and chemical properties of many systems and molecules covering a wide range of applications [12-14]. It provides data for molecular systems whenever the experimental techniques are limited and/or unavailable. Some calculated modeling parameters could be correlated to the reactivity of the studied molecular systems. It is stated earlier that the TDM and HOMO/LUMO bandgap energy are indicators for the reactivity of a given compound with its surrounding molecules. As the TDM increase, while the HOMO/LUMO bandgap decreased, the structure is considered reactive [15-17]. Molecular modeling with different level of theory show possibilities to investigate molecules of concern in biological as well as medical applications [18-21]. The MESP is also among important quantities describing the reactivity of a molecular system. Having MESP maps for various chemical entities is one of the remarkable benefits of molecular modeling computations [22]. MESP concept becomes common in the scientific community as it is capable of presenting accurate data regarding the functional, active areas for these chemical substances [23]. Furthermore, these maps are crucial in assessing the attitude of chemical addition reactions undergone by these structures, either electrophilic or nucleophilic chemical addition. Numerous articles were published previously 
involving several accounts on the molecular surface [24-26]. One of the well-known terms for molecular surface considers the constructed MESP maps as the peripheral area around a chemical entity which results from a collection of intersected spheres whose centers are ranged toward the nucleus of each one [27-32]; these supposed intersected spheres are yielded via forces such as van der Waals radii of the investigated atoms [33]. On the contrary, these maps were viewed [34-35] as the outer contour of electron densities $\rho(r)$. It is worthy of mentioning that the latter definition is more preferred than the aforementioned one as it includes more valuable and informative details concerning the chemical characteristics of the considered structures, for example, lone pair electrons, $\sigma$-holes presence, and many more. These contours have been ensured all the time to inform about $95-98 \%$ of the required details about the electronic density of structures [33, 34]. The calculated electrostatic potentials V(r) of some structure had been documented as the main part in governing its reactive behavior. Molecular modeling, together with QSAR, was utilized to elucidate the effect of substitution on the AZT [36], later extensive attention was paid to the effect of substitution upon the vibrational spectra of AZT [37]. Solvation describes the interaction of the solvent with dissolved molecules; it plays an important role in molecular recognition. Water has the power to dissolve more substances than any other liquid, and, because of this power, water is often referred to as the universal solvent [38]. The present work is conducted to elucidate the effect of first and second hydration on the electronic and vibrational spectra of AZT. First, hydration is indicated as five water molecules interact with AZT forming AZT. $5 \mathrm{H}_{2} \mathrm{O}$, then another 10 water molecules forming the second hydration shell, which is interacted with $A Z T .5 \mathrm{H}_{2} \mathrm{O}$, forming AZT. $15 \mathrm{H}_{2} \mathrm{O}$. The study is conducted with DFT at B3LYP/6-31G(d,p).

\section{Calculations details}

All the studied models are subjected to energy optimizations using Gaussian 09 [39] implemented on the personal computer at the spectroscopy Department, National Research Centre (NRC), Egypt. AZT and AZT hydrated models are optimized, then vibrational spectra were calculated at B3LYP/6-31G(d,p) [40-42] level of theory.

\section{Results and Discussion}

\subsection{Building model molecules.}

In this work, AZT, which indicated in figure 1, was subjected to energy optimization at B3LYP/6-31G(d,p) then subjected to vibrational frequency calculations at the same level. AZT is further subjected to hydration with water molecules.

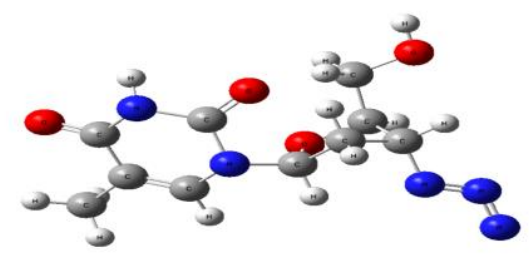

Figure 1. This Model molecule for the studied AZT.

As indicated in figure 1, there are five possible sites for hydration, the first through the hydrogen bonding of $\mathrm{NH}$ of the ring, as indicated in figure 2(a). Another water molecule is 
interacted in the second site at the hydrogen bonding of the $\mathrm{OH}$ of $\mathrm{CH}_{2} \mathrm{OH}$ to form di-hydrated AZT, as shown in figure 2(b).

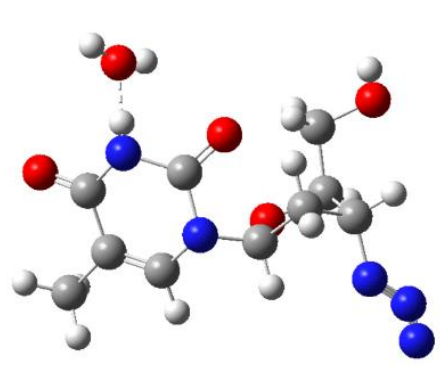

(a)

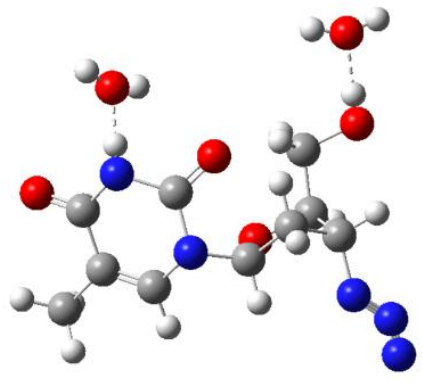

(b)

Figure 2. Model molecule for the studied AZT whereas, a- Water molecule has interacted through hydrogen bonding with the $\mathrm{H}$-atom of the $\mathrm{NH}$ of the ring, b- Water molecule has interacted through hydrogen bonding with the $\mathrm{H}$-atom of the $\mathrm{NH}$ of the ring, another one through the hydrogen bonding of the $\mathrm{OH}$ of $\mathrm{CH}_{2} \mathrm{OH}$.

For AZT hydrated with three water molecules, figure 3(a) showed that the third water molecule is added as hydrogen bonding to the $\mathrm{N}$ atom of $\mathrm{N}_{3}$. Two further water molecules could be added to the $\mathrm{N}_{3}$, as indicated in figures 3(b) and 4(a) to form AZT hydrated with four and five water molecules, respectively. All the studied five hydrated AZT represent the first hydration shell of AZT, another attempt to indicate hydration is the model at which AZT shows the second hydration shell, whereas 15 water molecules were surrounding the AZT molecules.

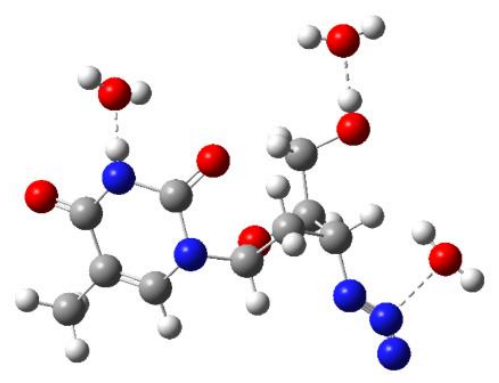

(a)

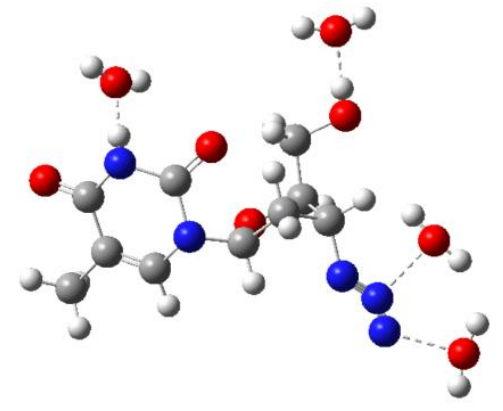

(b)

Figure 3. Model molecule for the studied AZT whereas, a- Water molecule has interacted through hydrogen bonding with the $\mathrm{H}$-atom of the $\mathrm{NH}$ of the ring, another one through the hydrogen bonding of the $\mathrm{OH}$ of

$\mathrm{CH}_{2} \mathrm{OH}$, the third one has interacted through one $\mathrm{N}$ of the $\mathrm{N}_{3}$, b- Water molecule has interacted through hydrogen bonding with the $\mathrm{H}$-atom of the $\mathrm{NH}$ of the ring, another one through the hydrogen bonding of the $\mathrm{OH}$ of $\mathrm{CH}_{2} \mathrm{OH}$ the third and fourth have interacted through two $\mathrm{N}$ atoms of the $\mathrm{N}_{3}$.

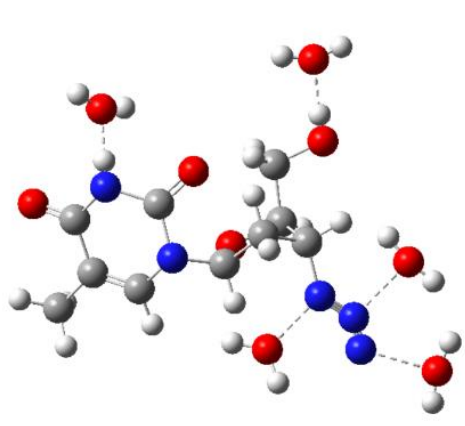

(a)

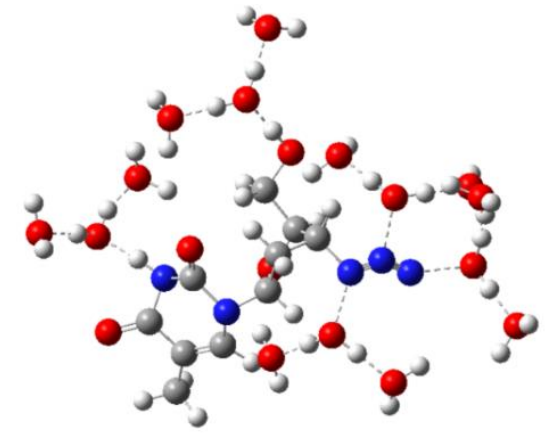

(b)

Figure 4. Model molecule for the studied AZT whereas, a- Water molecule has interacted through hydrogen bonding with the $\mathrm{H}$-atom of the $\mathrm{NH}$ of the ring, another one through the hydrogen bonding of the $\mathrm{OH}$ of $\mathrm{CH}_{2} \mathrm{OH}$, three water molecules have interacted through the $\mathrm{N}_{3}$, b- AZT subject to 15 water molecules 5 through the first hydration shell and 10 through the second hydration shell. 
As indicated in figure 4(b), each water molecule of the first hydration shell is surrounded by two water molecules forming the second hydration shell. In such a case, the AZT is hydrated with 15 water molecules. It is worth to mention that the studied hydrated AZT is subjected to geometry optimization calculation at B3LYP/6-31G(d,p). A focus will be pointed into the physical and vibrational parameters of AZT to indicate the effect of hydration.

\subsection{Structural and vibrational analyses.}

Table 1 presents the B3LYP/6-31G(d,p) calculated physical parameters for AZT as well as hydrated AZT. Based on frontiers energies, reactivity and many other physical characterizations are determined, such as optical band gap, electron tendency (A), ionization energy (I), hardenability $(\eta)$, chemical potential $(\mu)$, electrophilicity indicator $(\psi)$, plasticity $(\zeta)$ and finally overall dipole moment.
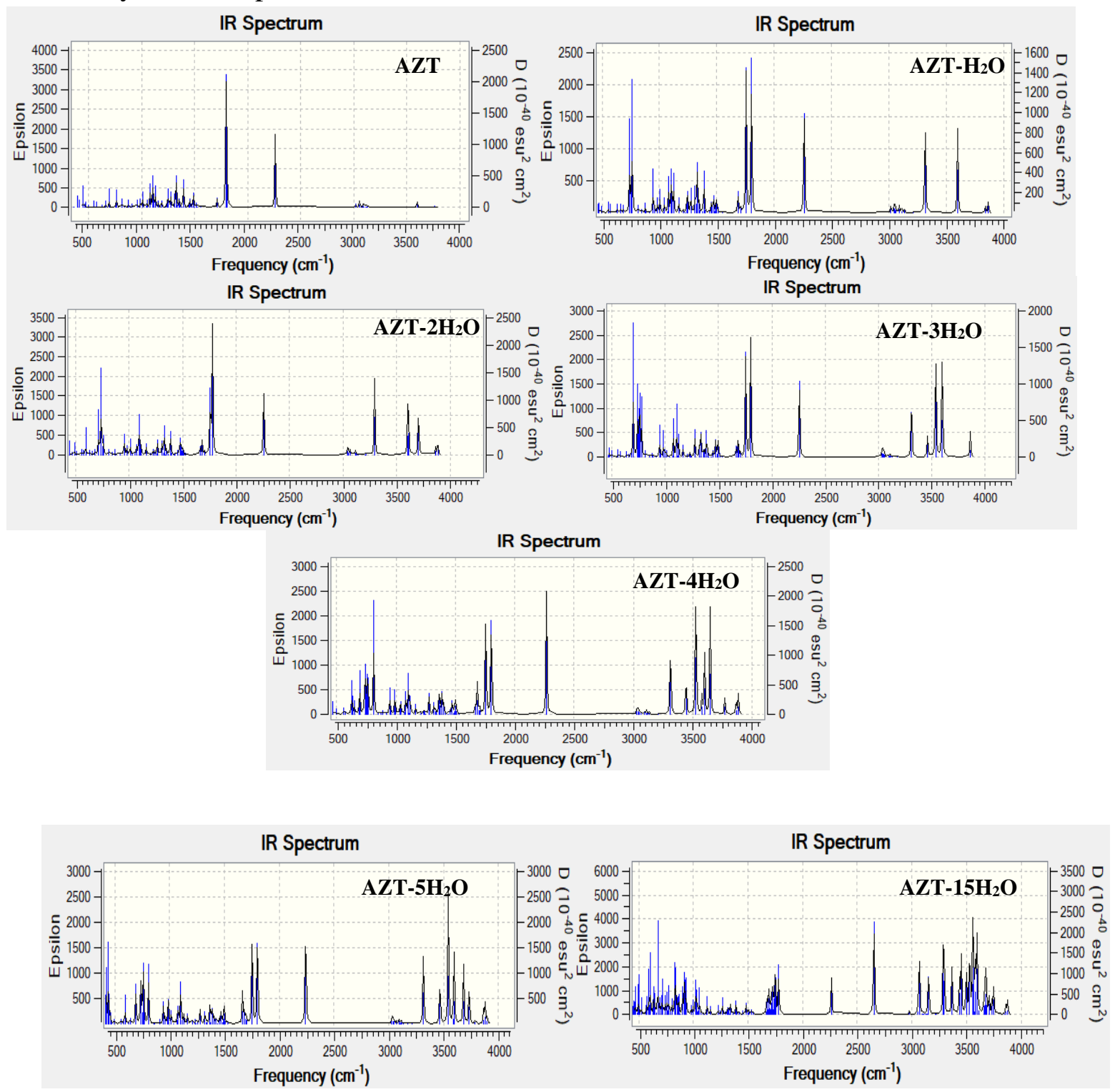

Figure 5. B3LYP/6-31G(d,p) calculated IR spectra for AZT, AZT. $\mathrm{H}_{2} \mathrm{O}, \mathrm{AZT} .2 \mathrm{H}_{2} \mathrm{O}$, AZT. $3 \mathrm{H}_{2} \mathrm{O}, \mathrm{AZT} .4 \mathrm{H}_{2} \mathrm{O}$, AZT. $5 \mathrm{H}_{2} \mathrm{O}$, and AZT. $15 \mathrm{H}_{2} \mathrm{O}$.

Among all such parameters, the dipole moment is highly affected by adsorption. The hydration procedure for AZT molecules has been checked by well-tested DFT:B3LYP/6$31 \mathrm{G}(\mathrm{d}, \mathrm{p})$ level to see the impact of adsorption of water molecules on AZT characteristics. The 
additive water molecule's impact has been investigated gradually from single, double, triple, and quadruple adsorption interplays' point of view.

In the first case, the water molecule is brought close to aromatic $\mathrm{NH}$ flake giving rise to $\mathrm{OH}$ stretching mode appearance at $3596 \mathrm{~cm}^{-1}$. It is remarkable that $\mathrm{NH}$ stretching has been lowered from 3599 to $3313 \mathrm{~cm}^{-1}$ for unhydrated AZT. Then, another water molecule is located close to $\mathrm{OH}$ terminal in addition to previously adding to $\mathrm{NH}$ flake. A blue shift is noticed all over $\mathrm{OH}$ stretchings from 3596 to $3883 \sim 3703 \mathrm{~cm}^{-1}$.

At the main time, $\mathrm{NH}$ stretching continues red-shifted to $3293 \mathrm{~cm}^{-1}$. An additive water molecule is adsorped to a centered $\mathrm{N}_{3}$ group proposing a high humidity condition. $\mathrm{OH}$ overtones are assigned at $3539 \mathrm{~cm}^{-1}$, whereas NH stretching moves upward to $3312 \mathrm{~cm}^{-1}$. Once more, the water molecule is dropped outside mid- $\mathrm{N}_{3}$, offering over-humidified behavior. As before, the latest $\mathrm{OH}$ overtone is scanned at $3442 \mathrm{~cm}^{-1}$, whereas $\mathrm{NH}$ stretching has remained unaffected. The calculated IR spectra for adsorption of water molecules on AZT are shown in figure 5 .

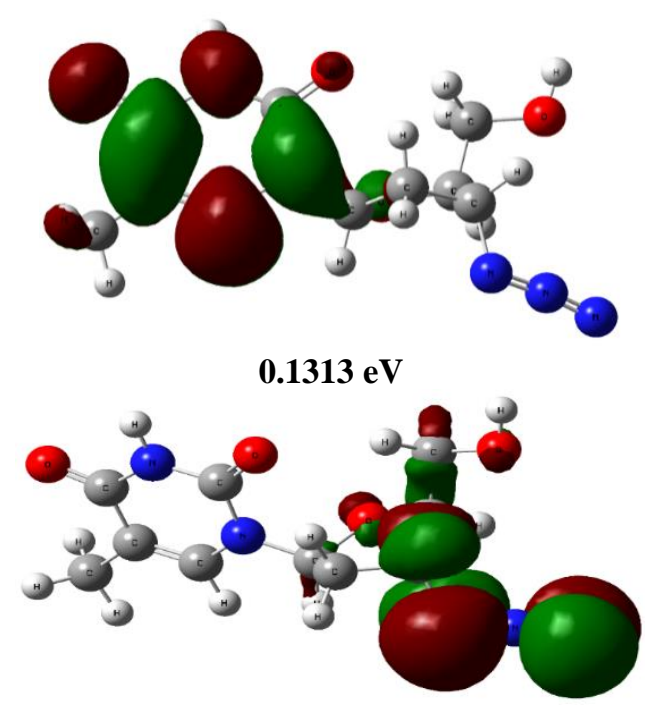

(a)

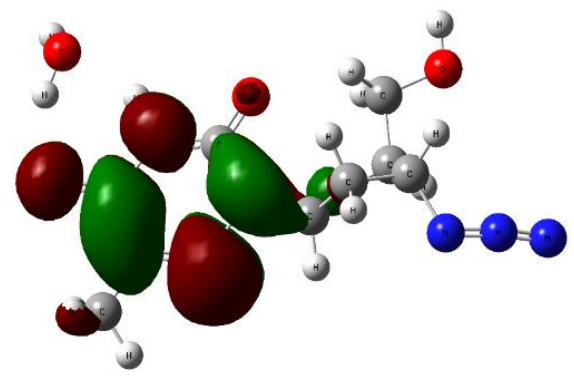

$0.1309 \mathrm{eV}$

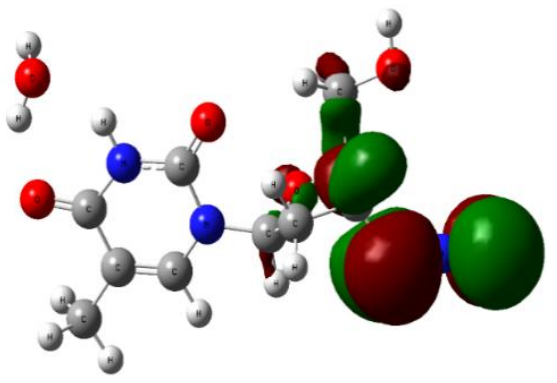

(b)

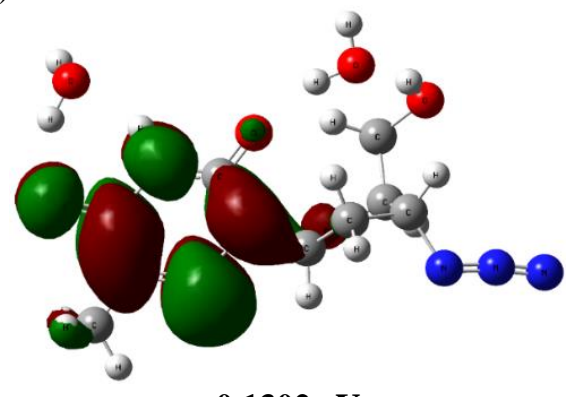

$0.1302 \mathrm{eV}$

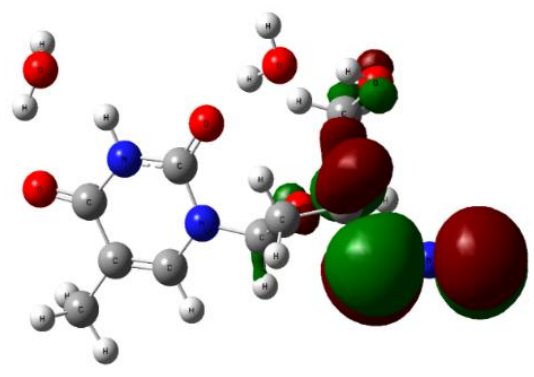

(c) 

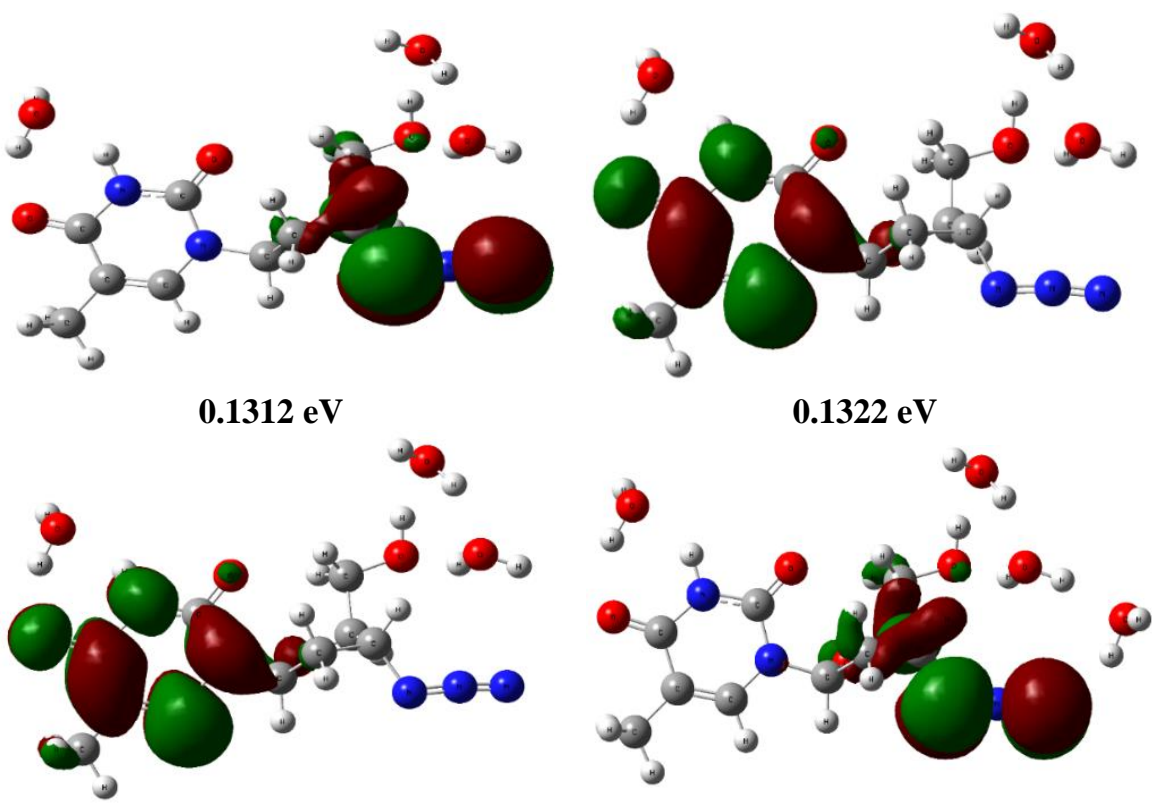

(d)

(e)
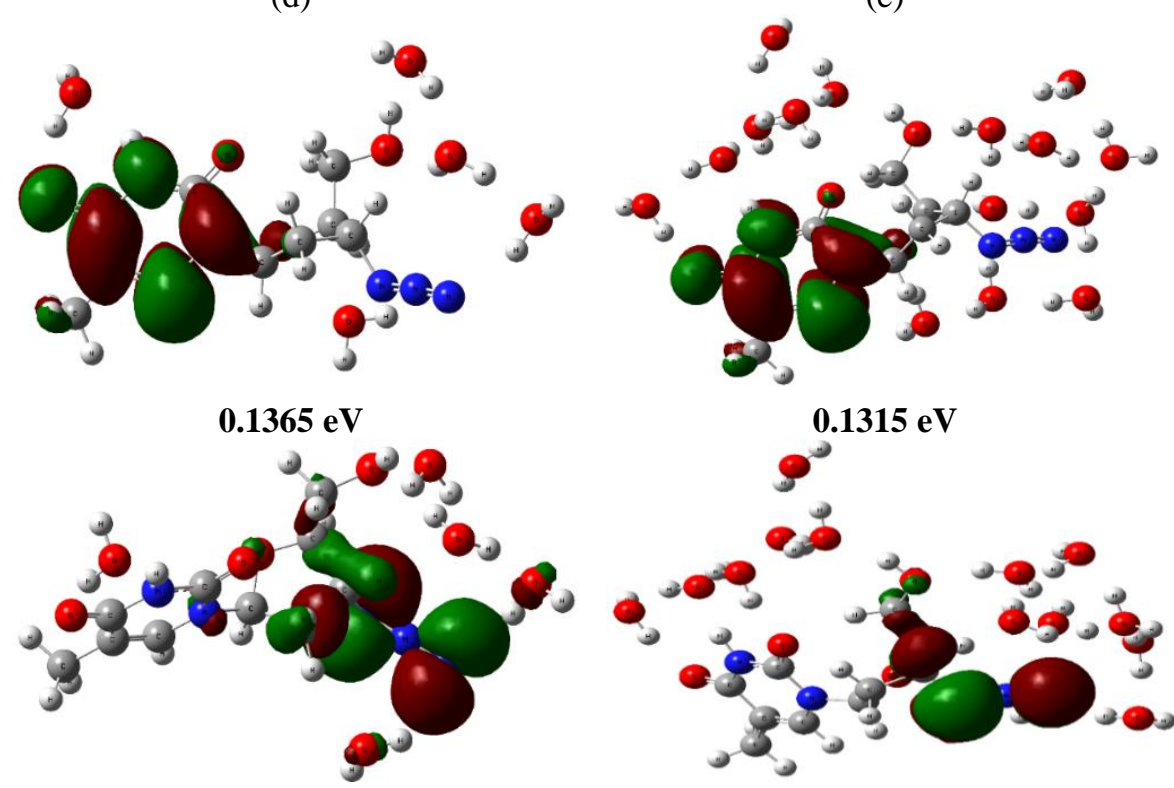

(f)

(g)

Figure 6. B3LYP/6-31G(d,p) calculated HOMO (lower) and LUMO (upper) molecular orbitals of (a) pure AZT structure, (b) AZT interacting with one water molecule, (c) two water molecules, (d) three water molecules, (e) four water molecules, (f) five water molecules and (g) 15 water molecules through $\mathrm{H}$-bonding with the $\mathrm{H}$-atom of the $\mathrm{NH}$ of the ring, the $\mathrm{OH}$ of $\mathrm{CH}_{2} \mathrm{OH}$, one, two and three $\mathrm{N}$ atoms of the $\mathrm{N}_{3}$ and 15 water molecules 5 through the first hydration shell and 10 through the second hydration shell, respectively at B3LYP/6-31G(d,p).

\subsection{Toal dipole moment and HOMO/LUMO bandgap energy.}

Geometry optimization calculations are carried out for investigating the impact of hydration of the AZT compound via one as well as two shell water molecules on its physical and electronic features. Such computations are conducted via DFT level at B3LYP/6-31G(d,p) method. Figure 6 presents the calculated HOMO/LUMO band gap energies $(\Delta \mathrm{E})$ for the proposed structures and their orbitals configuration, as well.

It is well known that the HOMO/LUMO band gap represents the amount of energy required for exciting some electron from the highest occupied molecular orbital (HOMO) to the lowest unoccupied molecular orbital (LUMO). Hence, it reflects the ease of having a conductive material. Therefore, bandgap can reflect the electrical activity of a substance. The resultant bandgap of AZT molecule equals $0.1313 \mathrm{eV}$, which is lowered as a result of adding 
both one and two water molecules for 0.1309 and $0.1302 \mathrm{eV}$, respectively. This reflects an increment in their electrical conductivity upon the addition of two water molecules. The addition of three water molecules has no significant effect on the calculated HOMO/LUMO bandgap. However, further addition of water, either in one or two shells, increases the obtained values. Hence, the addition of more than two water molecules to AZT affect its conductivity negatively. Moreover, figure 6 illustrates the mapped HOMO and LUMO orbitals for pure AZT structure as well as its hydrated forms. It is worthy to note that the LUMO orbitals are homogenously concentrated in the vicinity of the pyrimidine part of the AZT structure and its hydrated forms, as well. Similarly, the LUMO orbitals are shown to be distributed asymmetrically around both the deoxyribonucleoside portion as well as the terminal azido substituents (three $\mathrm{N}$ atoms). Both HOMO and LUMO orbitals distribute far away from the added water molecules except for the LUMO orbitals, which are found to be around water molecules making $\mathrm{H}$-bonding with two $\mathrm{N}$ atoms of the terminal azido substituents.

Figure 7 presents a comparison between the B3LYP/6-31G(d,p) calculated TDM and HOMO/LUMO bandgap energy for AZT, AZT. $\mathrm{H}_{2} \mathrm{O}$, AZT. $2 \mathrm{H}_{2} \mathrm{O}$, AZT, $3 \mathrm{H}_{2} \mathrm{O}$, AZT. $4 \mathrm{H}_{2} \mathrm{O}$, AZT. $5 \mathrm{H}_{2} \mathrm{O}$, and $\mathrm{AZT} .15 \mathrm{H}_{2} \mathrm{O}$. It is clear that increasing the water molecules increases the calculated TDM, as indicated in the figure. While the bandgap energy is slightly decreased as the number of water molecules increased. The water molecule is a polar molecule, which shows a great effect upon the TDM, which is affected by the polarity of the water molecule. Increasing the TDM is an indication of the increase in the reactivity of AZT as a result of increasing water molecules.

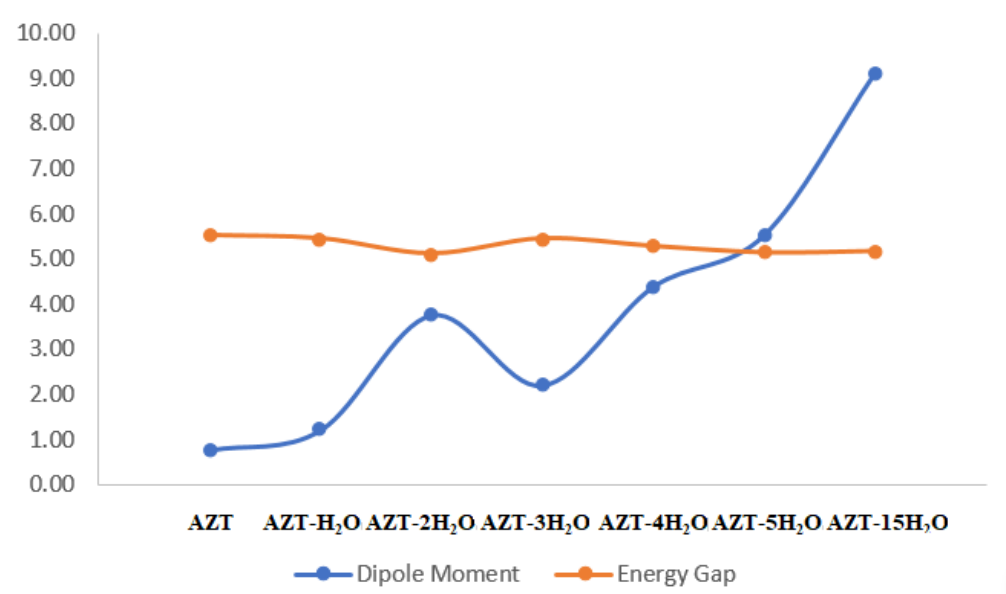

Figure 7. Comparison between B3LYP/6-31G(d,p) calculated TDM and HOMO/LUMO bandgap energy for AZT, AZT. $\mathrm{H}_{2} \mathrm{O}$, AZT. $2 \mathrm{H}_{2} \mathrm{O}$, AZT, $3 \mathrm{H}_{2} \mathrm{O}$, AZT. $4 \mathrm{H}_{2} \mathrm{O}$, AZT. $5 \mathrm{H}_{2} \mathrm{O}$, and AZT. $15 \mathrm{H}_{2} \mathrm{O}$.

\subsection{Molecular electrostatic potential.}

MESP maps are constructed for the studied pure and hydrated AZT structures at the DFT method using B3LYP/6-31G(d,p). They are always proving their ability to present both simple and quite well-established way for illustrating the distribution of electrical charges over a chemical structure and its most probable active sites.

Figure 8 shows the calculated MESP maps for AZT in the gaseous state and its hydrated structures with both first and second hydration shells. MESP maps usually composed of a wide range of rainbow colors go from red toward dark blue colors. 


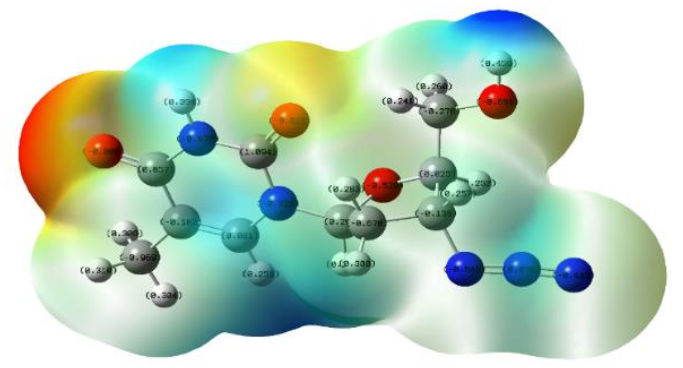

(a)

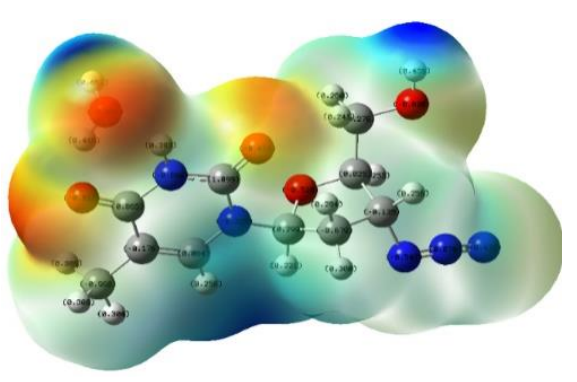

(b)

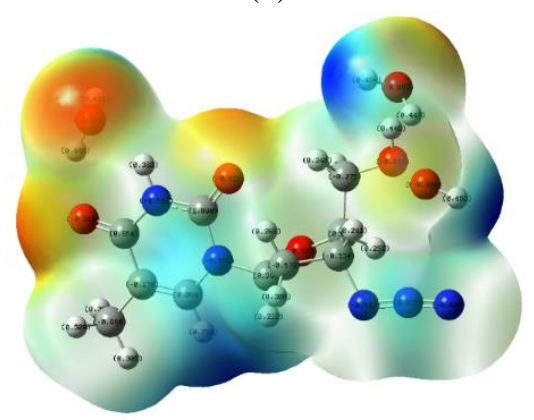

(d)

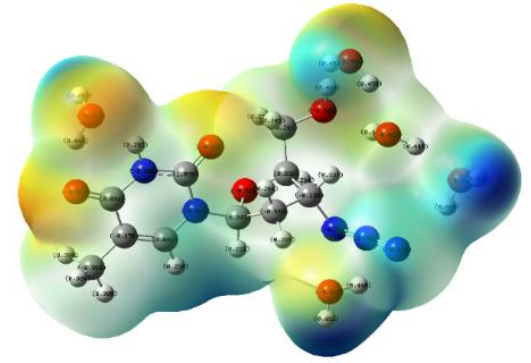

(f)

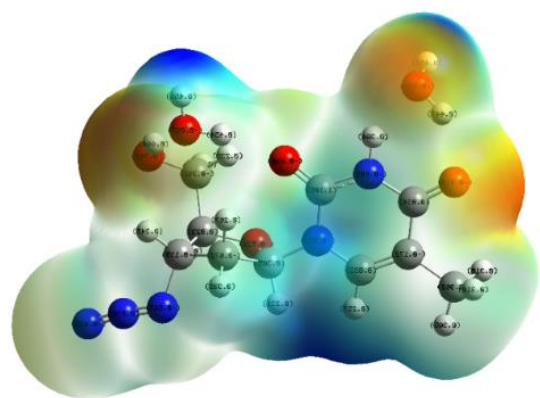

(c)

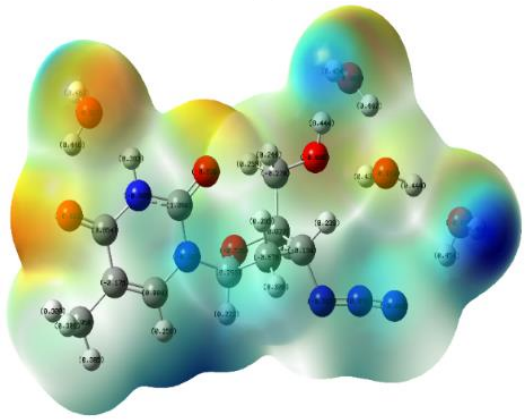

(e)

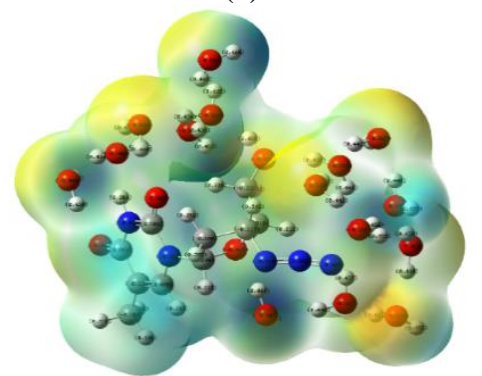

(g)

Figure 8. Calculated MESP maps of (a) pure AZT structure, (b) AZT interacting with one water molecule, (c) two water molecules, (d) three water molecules, (e) four water molecules, (f) five water molecules, and (g) 15 water molecules through $\mathrm{H}$-bonding with the $\mathrm{H}$-atom of the $\mathrm{NH}$ of the ring, the $\mathrm{OH}$ of $\mathrm{CH}_{2} \mathrm{OH}$, one, two and three $\mathrm{N}$ atoms of the $\mathrm{N}_{3}$ and 15 water molecules 5 through the first hydration shell and 10 through the second hydration shell, respectively DFT using B3LYP/6-31G(d,p) method.

These colors are utilized to represent regions of different electronegativity, where red corresponds to extreme negative areas and dark blue for positive ones. The full range of this rainbow colors consists of red, orange, yellow, green, light blue, and dark blue, where red is more electronegative than orange and yellow and so on. Hence, green may reflect regions of neutral potentials. MESP color distribution can be interrelated in some way with the electronegativity of the linked atoms where wide color distribution is obtained when atoms of significant difference in their electronegativity are bonded and vice versa. Therefore, MESP maps can be utilized as a physical characteristic in pointing out the nature of the chemical interaction in which structures may undergo (either nucleophilic or electrophilic). 
The constructed MESP maps of AZT pure and hydrated structures are composed of three main colors of the previously mentioned spectrum; red, light blue, and dark blue. This may be attributed to having four main atom types constructing the proposed structures; $\mathrm{C}, \mathrm{H}$, $\mathrm{N}$, and $\mathrm{O}$, where $\mathrm{O}$ and $\mathrm{N}$ atoms are more electronegative with respect to both $\mathrm{C}$ and $\mathrm{H}$ ones. This creates maps of well color distributions. Red color regions present where $\mathrm{O}$ atoms are due to their high electronegativity, and their binding to less electronegative atoms, e.g., $\mathrm{C}$ and $\mathrm{H}$. These terminal $\mathrm{O}$ atoms have a negative charge of more than $-0.8 \mathrm{C}$ while their bonded $\mathrm{C}$ atoms own positive charges of more than $0.85 \mathrm{C}$. This ensures the ability of AZT structure to undergo nucleophilic interactions through its terminal $\mathrm{O}$ atoms. Light blue sites are the most predominant in all of the constructed maps. They are found around $\mathrm{C}$ and internal $\mathrm{H}$ atoms, while terminal $\mathrm{H}$ ones appear in dark blue color because of their presence in the vicinity of the electronegative $\mathrm{O}$ atoms. Although $\mathrm{N}$ is one of the most electronegative species in the periodic table, they are colored here with light blue color. This may be attributed to the presence of three $\mathrm{N}$ atoms bonded with each other, which would cancel their high electronegativity effect. This assumption can be supported by revising the values of charges on those $\mathrm{N}$ atoms, as indicated in figure 8. The internal and outer $\mathrm{N}$ atoms have nearly the same negative charges of -0.546 and $-0.435 \mathrm{C}$, respectively while the intermediate one has a positive charge of $0.870 \mathrm{C}$. This ensures that the two terminal $\mathrm{N}$ atom successes in attracting the electrons away from the middle one causing the appearance of the light blue color. Such behavior indicates the capability of AZT to undergo electrophilic interactions through its terminal azido substituents, especially the middle $\mathrm{N}$ atom. The hydration of the AZT compound does not have a significant impact on the previously mentioned color or charge distribution until completing the first hydration shell. The addition of water accompanied by the appearance of additional red regions around $\mathrm{O}$ atoms of water molecules and dark blue color around their hydrogens where their charges are about $\sim-0.9$ and $\sim 0.4 \mathrm{C}$, respectively, reflecting the huge difference in their electronegativity. This may support the ability of AZT to go through both nucleophilic and electrophilic interactions. However, the formation of the second hydration shell significantly affects the original charge distribution in AZT.

Table 1. B3LYP/6-31G(d,p) calculated physical parameters for studied hydrated AZT.

\begin{tabular}{|c|c|c|c|c|c|c|c|}
\hline & AZT & $\begin{array}{c}\mathrm{AZT}- \\
\mathrm{H}_{2} \mathrm{O}\end{array}$ & $\begin{array}{l}\mathrm{AZT}- \\
2 \mathrm{H}_{2} \mathrm{O} \\
\end{array}$ & $\begin{array}{l}\mathrm{AZT}- \\
3 \mathrm{H}_{2} \mathrm{O} \\
\end{array}$ & $\begin{array}{l}\text { AZT- } \\
4 \mathrm{H}_{2} \mathrm{O} \\
\end{array}$ & $\begin{array}{l}\mathrm{AZT} \text { - } \\
5 \mathrm{H}_{2} \mathrm{O}\end{array}$ & $\begin{array}{c}\mathrm{AZT}- \\
15 \mathrm{H}_{2} \mathrm{O}\end{array}$ \\
\hline $\mathbf{E}_{\text {LUMO }}$ & -1.09 & -1.18 & -1.40 & -1.20 & -1.35 & -1.41 & -1.64 \\
\hline $\mathbf{E}_{\text {номо }}$ & -6.61 & -6.63 & -6.52 & -6.64 & -6.63 & -6.55 & -6.81 \\
\hline Energy Gap & 5.52 & 5.45 & 5.12 & 5.45 & 5.28 & 5.14 & 5.17 \\
\hline$A=-\mathbf{E}_{\text {номо }}$ & 1.09 & 0.04 & 1.40 & 0.04 & 0.05 & 1.41 & 1.64 \\
\hline $\mathbf{I}=-\mathbf{E}_{\text {LUMO }}$ & 6.61 & 0.24 & 6.52 & 0.24 & 0.24 & 6.55 & 6.81 \\
\hline$\eta=1 / 2\left(\mathrm{E}_{\text {LUMO }}-\mathrm{E}_{\text {HOMO }}\right)$ & 2.76 & 2.72 & 2.56 & 2.72 & 2.64 & 2.57 & 2.59 \\
\hline$\mu=1 / 2\left(E_{\text {LUMO }}+E_{\text {HOMO }}\right)$ & -3.85 & -3.91 & -3.96 & -3.92 & -3.99 & -3.98 & -4.23 \\
\hline$\psi=\mu^{2} / 2 \eta$ & 2.68 & 2.80 & 3.06 & 2.82 & 3.02 & 3.07 & 3.46 \\
\hline$\zeta=1 / n$ & 0.36 & 0.37 & 0.39 & 0.37 & 0.38 & 0.39 & 0.39 \\
\hline Dipole Moment & 0.77 & 1.22 & 3.76 & 2.20 & 4.39 & 5.53 & 9.12 \\
\hline
\end{tabular}

The second added shell converts all the red regions to yellow or reddish yellow ones, which results from a significant reduction in the negative charge on some $\mathrm{O}$ atoms. Though the $\mathrm{O}$ atoms of the added water molecules have nearly the same negative charges of those of the first layer, they also appear in yellow. This may be due to their presence close to each other, canceling their electronegative effects. 


\section{Conclusions}

AZT is hydrated through the first hydration shell (5 water molecules) and the second hydration shell (15 water molecules). DFT:B3LYP/6-31G(d,p) calculated results indicated that TDM is increased by increasing water molecules in contradicting HOMO/LUMO bandgap energy, which almost unchanged. Finally, the vibrational characteristics are also not changed as a result of hydration. The application of DFT for studying such a drug molecule proves that this method is an important computational tool for understanding molecular properties for many systems. This finding is in good agreement with the previous findings [43- 50].

\section{Funding}

This research received no external funding.

\section{Acknowledgments}

In this section, you can acknowledge any support given which is not covered by the author's contribution or funding sections. This may include administrative and technical support, or donations in kind (e.g., materials used for experiments).

\section{Conflicts of Interest}

The authors declare no conflict of interest.

\section{References}

1. Sharma, A. Various Biological Activities of DHA Derivatives. In: Dehydroacetic Acid and its Derivatives: Useful Synthons in Organic Synthesis. Edited by Santhosh, P. 2017; pp. 81-118, https://doi.org/10.1016/B978-0-08-101926-9.00005-5.

2. Peter, K.; Gambertoglio, J.G. Intracellular Phosphorylation of Zidovudine (ZDV) and Other Nucleoside Reverse Transcriptase Inhibitors (RTI) Used for Human Immunodeficiency Virus (HIV) Infection. Pharmaceutical Research 1998, 15, 819-825, https://doi.org/10.1023/A:1011956011207.

3. Denisko, O.V. Seven-membered Rings with Three Heteroatoms 1,3,5. Comprehensive Heterocyclic Chemistry III 2008, 13, 489-527, https://doi.org/10.1016/B978-0-08-096805-6.00016-4.

4. Vardanyan, R.S.; Hruby, V.J. 36-Antiviral Drugs. In: Synthesis of Essential Drugs. Vardanyan, R.S.; Hruby, V.J. Eds. Elsevier: Amsterdam, 2006; pp. 549-557, https://doi.org/10.1016/B978-044452166-8/50036-4.

5. Taylor, J.B.; Triggle, D.J. Therapeutic Areas II: Cancer, Infectious Diseases, Inflammation \& Immunology and Dermatology. Comprehensive Medicinal Chemistry II 2007, 7, 329-371.

6. Araújo, A.A.S.; Storpirtis, S.; x; lvia; Mercuri, L.P.; Carvalho, F.M.S.; Filho, M.d.S.; Matos, J.R. Thermal analysis of the antiretroviral zidovudine (AZT) and evaluation of the compatibility with excipients used in solid dosage forms. International Journal of Pharmaceutics 2003, 260, 303-314, https://doi.org/10.1016/S0378-5173(03)00288-6.

7. Jagetia, G.C.; Aruna, R. Correlation of micronuclei-induction with the cell survival in HeLa cells treated with a base analogue, azidothymidine (AZT) before exposure to different doses of $\gamma$-radiation. Toxicology Letters 2003, 139, 33-43, https://doi.org/10.1016/S0378-4274(02)00439-3.

8. $\quad$ da Rosa, R.M.; Piccoli, B.C.; da Silva, F.D.A.; Dornelles, L.; Rocha, J.B.T.; Sonego, M.S.; Begnini, K.R.; Collares, T.; Seixas, F.K.; Rodrigues, O.E.D. Synthesis, antioxidant and antitumoral activities of 5'arylchalcogeno-3-aminothymidine (ACAT) derivatives. MedChemComm 2017, 8, 408-414, https://doi.org/10.1039/C6MD00640J.

9. Guantai, E.M.; Ncokazi, K.; Egan, T.J.; Gut, J.; Rosenthal, P.J.; Smith, P.J.; Chibale, K. Design, synthesis and in vitro antimalarial evaluation of triazole-linked chalcone and dienone hybrid compounds. Bioorganic \& Medicinal Chemistry 2010, 18, 8243-8256, https://doi.org/10.1016/j.bmc.2010.10.009.

10. Dalpiaz, A.; Paganetto, G.; Pavan, B.; Fogagnolo, M.; Medici, A.; Beggiato, S.; Perrone, D. Zidovudine and Ursodeoxycholic Acid Conjugation: Design of a New Prodrug Potentially Able To Bypass the Active Efflux Transport Systems of the Central Nervous System. Molecular Pharmaceutics 2012, 9, 957-968, https://doi.org/10.1021/mp200565g. 
11. Chirumarry, S.; Soung, N.-K.; Han, J.; Kim, E.Y.; Ryu, E.K.; Lee, Y.-H.; Shin, S.Y.; Gunasekaran, P.; Bang, J.K. Antibacterial AZT derivative regulates metastasis of breast cancer cells. European Journal of Medicinal Chemistry 2020, 193, https://doi.org/10.1016/j.ejmech.2020.112233.

12. Omar, A.; Ezzat, H.; Elhaes, H.; Ibrahim, M.A. Molecular Modeling Analyses for Modified Biopolymers. Biointerface Res. Appl. Chem. 2021, 11, 7847-7859, https://doi.org/10.33263/BRIAC111.78477859.

13. Ezzat, H.; Menazea, A.A.; Omara, W.; Basyouni, O.H.; Helmy, S.A.; Mohamed, A.A.; Tawfik, W.; Ibrahim, M. DFT:B3LYP/ LANL2DZ Study for the Removal of $\mathrm{Fe}, \mathrm{Ni}, \mathrm{Cu}, \mathrm{As}, \mathrm{Cd}$ and $\mathrm{Pb}$ with Chitosan. Biointerface Res. Appl. Chem. 2020, 10, 7002-7010, https://doi.org/10.33263/BRIAC106.70027010.

14. Refaat, A.; Ibrahim, M.A.; Elhaes, H.; Badry, R.; Ezzat, H.; Yahia, I.S.; Zahran, H.Y.; Shkir, M. Geometrical, vibrational, and physical properties of polyvinyl chloride nanocomposites: Molecular Modeling Approach. J. Theor. Comput. Chem. 2020, 18.

15. Ibrahim, M.; Koglin, E. Vibrational Spectroscopic Study of Acetate Group. Acta Chimica Slovenica 2004, 51, 453-459.

16. Ibrahim, M.; Elhaes, H. Computational Spectroscopic Study of Copper, Cadmium, Lead and Zinc Interactions in the Environment. Int. J. Environment and Pollution 2005, 23, 417-424, https://doi.org/10.1504/IJEP.2005.007604.

17. Ibrahim, M.; Mahmoud, A.A. Computational Notes on the Reactivity of Some Functional Groups. Journal of Computational and Theoretical Nanoscience 2009, 6, 1523-1526, https://doi.org/10.1166/jctn.2009.1205.

18. Ibrahim, M.; Saleh, N.A.; Elshemey, W.M.; Elsayed, A.A. Hexapeptide functionality of cellulose as NS3 protease inhibitors. Med Chem 2012, 8, 826-830, https://doi.org/10.2174/157340612802084144.

19. Fahim, A.M.; Shalaby, M.A.; Ibrahim, M.A. Microwave-assisted synthesis of novel 5-aminouracil-based compound with DFT calculations. Journal of Molecular Structure 2019, 1194, 211-226, https://doi.org/10.1016/j.molstruc.2019.04.078.

20. Gawad, A.E.-D.A.; Ibrahim, M. Computational Studies of the Interaction of Chitosan Nanoparticles and $\alpha \mathrm{B}-$ Crystallin. BioNanoScience 2013, 3, 302-311, https://doi.org/10.1007/s12668-013-0096-3.

21. Galal, A.M.F.; Atta, D.; Abouelsayed, A.; Ibrahim, M.A.; Hanna, A.G. Configuration and molecular structure of 5-chloro-N-(4-sulfamoylbenzyl) salicylamide derivatives. Spectrochimica Acta Part A: Molecular and Biomolecular Spectroscopy 2019, 214, 476-486, https://doi.org/10.1016/j.saa.2019.02.070.

22. El-Mansy, M.A.M.; El-Nahass, M.M. On the spectroscopic analyses of Perylene-66. Spectrochimica Acta Part A: Molecular and Biomolecular Spectroscopy 2014, 130, 568-573, https://doi.org/10.1016/j.saa.2014.03.118.

23. Bulat, F.A.; Toro-Labbé, A.; Brinck, T.; Murray, J.S.; Politzer, P. Quantitative analysis of molecular surfaces: areas, volumes, electrostatic potentials and average local ionization energies. Journal of Molecular Modeling 2010, 16, 1679-1691, https://doi.org//10.1007/s00894-010-0692-x.

24. Bayoumy, A.M.; Elhaes, H.; Osman, O.; Hussein, T.; Ibrahim, M.A. Mapping molecular electrostatic potential for heme interacting with nano metal oxides. Biointerface Res. Appl. Chem. 2020, 10, 5091-5095, https://doi.org/10.33263/BRIAC0102.091095.

25. Bayoumy, A.M.; Ibrahim, M.; Omar, A. Mapping molecular electrostatic potential (MESP) for fulleropyrrolidine and its derivatives. Optical and Quantum Electronics 2020, 52, https://doi.org/10.1007/s11082-020-02467-6.

26. Al-Bagawi, A.H.; Bayoumy, A.M.; Ibrahim, M.A. Molecular modeling analyses for graphene functionalized with Fe3O4 and NiO. Heliyon 2020, 6, https://doi.org/10.1016/j.heliyon.2020.e04456.

27. Connolly, M.L. Solvent-accessible surfaces of proteins and nucleic acids. Sci. 1983, 221, 709-713, https://doi.org/10.1126/science.6879170.

28. Dunitz, J.D.; Filippini, G.; Gavezzotti, A. A Statistical Study of Density and Packing Variations among Crystalline Isomers. Tetrahedron 2000, 56, 6595-6601, https://doi.org/10.1016/S0040-4020(00)00460-9.

29. Arteca, G.A.; Jammal, V.B.; Mezey, P.G.; Yadav, J.S.; Hermsmeier, M.A.; Gund, T.M. Shape group studies of molecular similarity: relative shapes of Van der Waals and electrostatic potential surfaces of nicotinic agonists. Journal of Molecular Graphics 1988, 6, 45-53, https://doi.org/10.1007/s11082-020-02467-6.

30. Francl, M.M.; Hout, R.F.; Hehre, W.J. Representation of electron densities. 1. Sphere fits to total electron density surfaces. Journal of the American Chemical Society 1984, 106, 563-570, https://doi.org/10.1021/ja00315a018.

31. Lee, B.; Richards, F.M. The interpretation of protein structures: Estimation of static accessibility. Journal of Molecular Biology 1971, 55, 379-IN374, https://doi.org/10.1016/0022-2836(71)90324-x.

32. Weiner, P.K.; Langridge, R.; Blaney, J.M.; Schaefer, R.; Kollman, P.A. Electrostatic potential molecular surfaces. Proceedings of the National Academy of Sciences 1982, 79, 3754-3758, https://doi.org/10.1073/pnas.79.12.3754.

33. Bondi, A. van der Waals Volumes and Radii. The Journal of Physical Chemistry 1964, 68, 441-451, https://doi.org/10.1021/j100785a001.

34. Bader, R.F.W.; Carroll, M.T.; Cheeseman, J.R.; Chang, C. Properties of atoms in molecules: atomic volumes. Journal of the American Chemical Society 1987, 109, 7968-7979, https://doi.org/10.1021/ja00260a006. 
35. Bader, R.F.W.; Henneker, W.H.; Cade, P.E. Molecular Charge Distributions and Chemical Binding. The Journal of Chemical Physics 1967, 46, 3341-3363, https://doi.org/10.1063/1.1841222.

36. Essa, A.; Ibrahim, M.; Hameed, A.J.; Al-Masoudi, N. Theoretical investigation of 3'-subtituted-2'-3'dideoxythymidines related to AZT. QSAR infrared and substituent electronic effect studies. Arkivoc: archive for organic chemistry 2008, 2008.

37. Al-Fifi, Z.; Eid, M.; Saleh, N.A.; Ibrahim, M. Molecular Modelling Analyses of the Substituted AZT. J. Comput. Theor. Nanosci. 2014, 11, 409-412, https://doi.org/10.1166/jctn.2014.3369.

38. Speight, J.G. Chapter 3-Water chemistry. In: Natural Water Remediation, Chemistry and Technology. 2020; pp. 91-129, https://doi.org/10.1016/B978-0-12-803810-9.00003-6.

39. Frisch, M.; Trucks, G.; Schlegel, H.B.; Scuseria, G.E.; Robb, M.A.; Cheeseman, J.R.; Scalmani, G.; Barone, V.; Mennucci, B.; Petersson, G.J.I. Gaussian, Inc., Wallingford CT, 2009.

40. Becke, A.D. Density-functional thermochemistry. III. The role of exact exchange. The Journal of Chemical Physics 1993, 98, 5648-5652, https://doi.org/10.1063/1.464913.

41. Lee, C.; Yang, W.; Parr, R.G. Development of the Colle-Salvetti correlation-energy formula into a functional of the electron density. Physical Review B 1988, 37, 785-789, https://doi.org/10.1103/PhysRevB.37.785.

42. Vosko, S.H.; Wilk, L.; Nusair, M. Accurate spin-dependent electron liquid correlation energies for local spin density calculations: a critical analysis. Canadian Journal of Physics 1980, 58, 1200-1211, https://doi.org/10.1139/p80-159.

43. Abdelsalam, H.; Saroka, V.A.; Ali, M.; Teleb, N.H.; Elhaes, H.; Ibrahim, M.A. Stability and electronic properties of edge functionalized silicene quantum dots: A first principles study. Physica E: Lowdimensional Systems and Nanostructures 2019, 108, 339-346, https://doi.org/10.1016/j.physe.2018.07.022.

44. Grenni, P.; Barra Caracciolo, A.; Mariani, L.; Cardoni, M.; Riccucci, C.; Elhaes, H.; Ibrahim, M.A. Effectiveness of a new green technology for metal removal from contaminated water. Microchemical Journal 2019, 147, 1010-1020, https://doi.org/10.1016/j.microc.2019.04.026.

45. Nematov, D.D.; Burhonzoda, A.S.; Khusenov, M.A.; Kholmurodov, K.; Ibrahim, M.J.T.E.J.o.C. The Quantum-Chemistry Calculations of Electronic Structure of Boron Nitride Nanocrystals with Density Functional Theory Realization. E.J. Chem. 2019, 62, 21-27, https://doi.org/10.21608/EJCHEM.2019.12879.1805.

46. Elgabaly, S.; Youssif, G.; Bayoumy, A.; Ezzat, H.; Elhaes, H.; Ibrahim, M. Modeling the Effect of functional groups on the electronic properties of benzene, pyridine and pyrimidine. Egyptian Journal of Chemistry 2019, 62, 15-17.

47. Doroshkevich, O.; Nabiev, A.A.; Shylo, A.; Pawlukojć, A.; Doroshkevich, V.S.; Glazunova, V.A.; Zelenyak, T.Y.; Doroshkevich, N.; Rahmonov, K.R.; Khamzin, E.; Nematov, D.D.; Burhonzoda, A.S.; Khusenov, M.; Kholmurodov, K.; Majumder, S.; Balasoiu, M.; Madadzada, A.; Bodnarchuk, V.I. Frequency modulation of the Raman spectrum at the interface DNA - ZrO2 nanoparticles. Egyptian Journal of Chemistry 2019, 62, 13-15, https://doi.org/10.21608/EJCHEM.2019.12898.1806.

48. Ghashghaee, M.; Azizi, Z.; Ghambarian, M. Conductivity tuning of charged triazine and heptazine graphitic carbon nitride (g-C3N4) quantum dots via nonmetal (B, O, S, P) doping: DFT calculations. Journal of Physics and Chemistry of Solids 2020, 141, https://doi.org/10.1016/j.jpcs.2020.109422.

49. Mohammadi-rad, N.; Esrafili, M.D.; Sardroodi, J.J. CuN3 doped graphene as an active electrocatalyst for oxygen reduction reaction in fuel cells: A DFT study. Journal of Molecular Graphics and Modelling 2020, 96, https://doi.org/10.1016/j.jmgm.2020.107537.

50. Singh, S.; Kaur, I. Bandgap engineering in armchair graphene nanoribbon of zigzag-armchair-zigzag based Nano-FET: A DFT investigation. Physica E: Low-dimensional Systems and Nanostructures 2020, 118, https://doi.org/10.1016/j.physe.2020.113960. 